\title{
Do espectador pensativo à imagem pensativa: fotografia e filme-ensaio
}

\section{From the pensive spectator to pensive image: photo and essay-film}

\author{
Rafael de Almeida
}

Doutor em Multimeios pela Universidade Estadual de Campinas (UNICAMP). Professor do curso de Cinema e Audiovisual da Universidade Estadual de Goiás (UEG).

$<$ rafaeldealmeidaborges@gmail.com>

\section{RESUMO}

O presente artigo pretende refletir sobre os possíveis desdobramentos e/ou efeitos gerados pelo uso da fotografia fixa, enquanto material de composição, na feitura de um filme-ensaio. Partimos do pressuposto que a presença da foto na tela de cinema é capaz de gerar um efeito de suspensão no ritmo do filme. Por meio desse congelamento temporal é possível que o espectador se desvencilhe, ao menos em parte, do fluxo narrativo e se permita pensar no cinema. Por tal perspectiva, pretendemos realizar uma análise fílmica do curta-metragem A festa e os cães (Leonardo Mouramateus, 2015), para, enfim, propor que o uso da imagem fixa no filme-ensaio, em particular, para além de reforçar a convocação deu um "espectador pensativo", é capaz de gerar uma "imagem pensativa".

Palavras-chave: Filme-ensaio. Fotografia. A festa e os cães (filme).

\begin{abstract}
This article aims to reflect on the possible consequences and/or effects by the use of still photography, as composite material, in the making of a essay-film. I assume that the picture's presence in movie screen is capable of generating a suspension effect on the pace of the film. By this time freezing is possible that the spectator unfasten, at least in part, the narrative flow and allow yourself to think in cinema. For this perspective, we intend to conduct a filmic analysis of the short film The party and the barking (Leonardo Mouramateus, 2015), to finally propose that the use of the still image in the essay-film, in particular, in addition to strengthening the convocation a "pensive spectator" is able to generate a "pensive image".
\end{abstract}

Keywords: Essay-film. Photography. The party and the barking (film).

\section{A festa e os cães: em busca de um espectador pensativo}

Um narrador cantarola: "Panan-panan... pananananananan.... Sobre a textura de um papel pardo, em plano detalhe fixo, aparecem os créditos iniciais do filme. "Em 20 de dezembro de 2013 comprei uma câmera fotográfica. Eu estava no meio das filmagens de um curta-metragem, mas àquela hora eu ajudava uma amiga na escolha do presente para seu namorado. Então, quando eu vi a câmera, me pareceu uma boa ideia registrar os bastidores do filme que estávamos fazendo", ele diz. Logo em seguida uma fotografia invade o plano, em um movimento ascendente da direita para esquerda, cobrindo completamente o quadro: a sensação que temos é de uma mão que segura a foto e a deposita diante da lente da câmera. Enquanto observamos a imagem fixa, com desfoque de movimento em seu plano de fundo, do rosto de um homem jovem que encara 
a câmera dentro de uma loja; ouvimos: "A primeira foto que a câmera tirou foi essa, feita pela dona da loja, me mostrando como usar a câmera. Este sou eu. Eu estou bem feio". Esse é o início de A festa e os cães (Leonardo Mouramateus, 2015).

A partir de então, o filme em sua quase totalidade se desenvolve a partir dessa mise-en-scène: fotos vão paulatinamente sendo sobrepostas, umas sobre as outras, diante da câmera que as filma. Dessa maneira, o único movimento que acompanhamos é das próprias fotografias tomando o quadro. Movimento gerado por uma mão que quase nunca vemos, apenas imaginamos. Prevalece no filme, portanto, a paralisação, a imobilização e o congelamento da imagem fotográfica; em detrimento do movimento da imagem de cinema.

O que acontece com o espectador ao, logo nos primeiros instantes de A festa e os cães, ser presenteado com uma fotografia? Bellour responderia que a "presença da foto na tela produz [...] uma emoção muito particular. Sem deixar de prosseguir em seu ritmo, o filme parece congelar-se, suspender-se, criando no espectador um recuo que é acompanhado por um aumento do fascínio" (Bellour, 1997, p. 85). No entanto, depois da primeira foto, o filme de Mouramateus continua a apresentar outras incessantemente, de maneira tal que passamos a saltar de uma suspensão a outra, mantendo-nos continuamente em um estado de congelamento. $\mathrm{O}$ qual compreendemos como uma circunstância de descontinuidade, interrupção e paralisação percebida pelo espectador como efeito da estabilização da imagem ao solidificar o movimento.

Por essa via, as fotos deixam de comportar-se simplesmente como objetos diante da lente e passam a ser percebidas como materiais de composição que, em relação criativa com os demais, em especial a voz over, contribuem para a criação de um universo fílmico singular.

Nesse sentido, poderíamos pensar que o deslumbre gerado por esse afastamento seria potencializado em filmes que exploram amplamente o recurso da fotografia fixa, sendo constituídos completamente, ou em sua maior parte, por fotografias. Slide-motion film é o termo que costuma nomear esse tido de obra. Segundo Konigsberg tratam-se de filmes, "geralmente documentários, que utilizam uma série de imagens fixas como um filmógrafo, mas no qual a câmera parece mover-se entre os elementos das imagens mediante um objetivo de panorâmica ou zoom" (Konigsberg, 2004, p. 508, tradução nossa). Outros termos comumente utilizados são "foto-novela", "foto-filme" ou mesmo "foto-romance", como o inaugural La jetée (Chris Marker, 1962) é apresentado. O que nos leva a perceber que os filmes são compreendidos tão somente pela 
perspectiva da fotografia, tendo tal sinalização em sua própria grafia, pelo uso de "foto" como prefixo.

Nenhuma das definições acima, em seus contextos semânticos originais, nos parece apropriada para abarcar esses filmes. Em maior ou menor grau, todas elas parecem operar um reducionismo da potência expressiva das obras - em especial, dos modos distintos da construção do espaço fílmico e da temporalidade, em um forte diálogo com a narração - a apenas uma de suas características mais evidentes: o uso de imagens fixas.

Por essa perspectiva, parece-nos apropriada a atualização do conceito de slide-motion film proposta por Liv Hausken (2011). De acordo com o autor, para incluirmos La jetée e outros filmes semelhantes, em torno à definição discutida, e adensar o conceito, deveríamos compreender o significado elementar de slide enquanto imagem projetada, uso de fotografia na tela, mais que um movimento de câmera de deslizamento sobre determinada superfície imagética. Desse modo, o movimento gerado, então, passa a referir-se menos ao movimento de câmera em si que à impressão de movimento gerada pela sequência de imagens.

A partir dessa atualização, fica evidente que há uma mudança significativa na ênfase operada pelo conceito:ainda que os filmes sejam realizados geralmente apenas pelo uso de fotografias, a nossa atenção se transfere da fixidez da imagem fotográfica enquanto elemento isolado para o movimento inerente ao conjunto de imagens, para o fluxo constante que emana dos encontros entre uma foto e outra gerados pelo filme.

A proposição de Hausken parece reverberar na técnica de kinestasis, elucidada pelo próprio Konigsberg, que abrange a "utilização de imagens fixas na realização de um filme. Estas imagens podem ser fotografias, pinturas, desenhos, collages, ou uma série de imagens congeladas de um filme" (Konigsberg, 2011, p. 282). Os usos podem se dar de diversas maneiras, tais como: 1) aparição descontínua de cada imagem, por determinados segundos, a cada vez; 2) movimento de imagens fixas diante da câmera; 3) panorâmica, zoom-in ou zoom-out da câmera sobre as imagens; 4) aparição de uma série de imagens fixas. As intenções de tais usos costumam girar em torno à criação de efeitos perceptivos ou sensação de movimento, tempo e/ou lugar. Tendo esse panorama em vista, parece-nos que a ampliação do termo slide-motion film vai ao encontro direto de obras que utilizam fundamentalmente a técnica de kinestasis em sua confecção.

Com essa nova compreensão do termo em vista, ele poderia ser usado para qualquer tipo de filme que se apresenta como uma composição de imagens fotográficas de qualquer tipo. Nesse sentido, passamos a compreender 
o slide-motion film "como uma forma de expressão fílmica, como uma forma particular de stasis dentro do campo das imagens em movimento" (Hausken, 2011, p. 91, tradução nossa). Por meio de tal compreensão, portanto, ficam superadas as dicotomias existentes entre kinesis e stasis, cinema e fotografia, mobilidade e fixidez. O movimento é inerente à forma fílmica, mesmo em obras que se valem inteiramente de imagens fixas. Mesmo nelas o movimento está presente, preenchendo cada intervalo - esse espaço entre uma imagem e outra - e convocando o espectador a criar outras imagens.

Ao nos depararmos com a imagem fixa no cinema encontramos tempo para adicionar algo ao quadro, à fotografia, ao slide. Um tempo garantido pela duração de cada plano imóvel na tela. Nesse instante, impulsionados pela kinestasis, agregamos sobretudo movimento - motion - ao filme que vemos, propondo conexões entre as imagens pela possibilidade e convite de pensar o filme durante sua própria projeção.

Nesse sentido Bellour escreveu: "Nisso, a foto tem um privilégio sobre todos os efeitos por meio dos quais o espectador de cinema, esse espectador apressado, torna-se também um espectador pensativo" (Bellour, 1997, p. 93). 0 uso da fotografia no cinema garante, então, a possibilidade da existência de um espectador pensativo, uma audiência que reflita sobre as imagens que vê. Isso se dá, essencialmente, pela mistura de dois tempos distintos: o do filme e o da fotografia. Enquanto o primeiro, por meio da mise-en-scène, em geral nos seduz em direção a um tempo imaginado e incontrolável; o segundo, por meio da fixidez, nos convence de nosso lugar enquanto espectadores, convidando-nos à pensar.

Dessa maneira, se podemos perceber a fotografia como indício visual de um convite ao espectador para exercitar o pensamento e a reflexão dentro do cinema, quais seriam os desdobramentos de um slide-motion film que se proponha a ser um filme-ensaio, como é o caso de $A$ festa e os cães? Tendemos a crer que esse encontro de características gera um duplo deslocamento no espectador: se a fotografia "arranca o espectador desta força pouco precisa, mas pregnante: a mediação imaginária do cinema" (Bellour, 1997, p. 93); o filme-ensaio se valerá dela, e de uma série de outros recursos retóricos, para arrebatá-lo ainda mais de tal força, propondo que ele vá além de um espectador pensativo.

\section{O filme-ensaio e a dupla mediação}

A festa e os cães, enquanto filme-ensaio, extrai o espectador da mediação imaginária do cinema justamente ao evidenciar as mediações que opera, para 
se constituir enquanto discurso, por meio de sua própria forma. O comentário verbal e a montagem são as técnicas que estabelecem essa mediação e que o cinema possui para produzir-se como ensaio (Weinrichter, 2007). Utilizadas por Mouramateus, são elas que modificam a significação e a força das fotografias que maneja, criando um espaço reflexivo e associativo onde o espectador baseado em sua própria experiência com a juventude, as relações de amizade, fotos pessoais com amigos e despedidas - é chamado a deixar-se levar pela identificação e memória.

Por essa via, os filmes-ensaio solicitam aos espectadores que "experimentem o mundo no sentido intelectual e fenomenológico pleno dessa palavra como o encontro mediado do pensar o mundo, como um mundo experimentado por meio de uma mente pensante" (Corrigan, 2015, p. 39-40). Ou seja, o ensaísta audiovisual parte de uma inquietação pessoal - no caso de A festa e os cães trata-se da consciência da despedida próxima dos amigos e de todo o universo que eles fazem parte em Fortaleza - para refletir sobre questões que vão de encontro à esfera pública, que podem ser compartilhadas com uma determinada comunidade, de tal modo que o filme se converta no resultado desse processo reflexivo e dialógico, em uma forma que pensa.

Fica evidente, portanto, que partimos do pressuposto de que o filmeensaio assume para si a tarefa de convocar seus espectadores à atividade, garantindo por meio de sua própria escritura lacunar os espaços necessários para que a narrativa se torne, assim, resultado dos esforços do realizador e do espectador. Sendo assim, ao paradoxo do espectador de Rancière (2012), que nos diz que uma obra, e nos interessa pensar especificamente o filme-ensaio, sempre prevê a existência de um espectador; Comolli (2008) acrescenta outro paradoxo. Na esteira do autor, pensamos que ao partir do evidente caráter de mediação empreendido pelo cinema ensaístico, caberia ao espectador propor uma dança com a obra, entre crença e dúvida, para seguir avançando. Crer, mas ao mesmo tempo duvidar. Sendo assim, o filme-ensaio realiza uma dupla mediação em diferentes sujeitos e momentos: no realizador durante a construção da obra e no espectador durante a sua exibição. Circunstanciemos.

O primeiro aspecto dessa mediação está ligado ao fato de que o ensaísta audiovisual submete a sua experiência subjetiva por meio de um ordenamento conceitual particular, que atende à princípio aos anseios de seu próprio pensamento, pelo interior da escritura fílmica. Isto é, a construção do filme medeia a experiência singular do cineasta com o mundo e o processo reflexivo fruto desse encontro com a esfera pública converte-se na própria obra, em imagens e sons. A escritura de corolário autobiográfico das obras ensaiam, 
portanto, um aprendizado sobre os próprios sujeitos que a empreendem e o mundo que se dá a ver no momento de sua feitura. Um aprendizado a ser compartilhado mediante à tela de cinema.

O segundo aspecto se relaciona ao acontecimento de que o filme-ensaio realiza uma mediação da experiência entre as coisas do mundo e os espectadores que estão diante da tela, especialmente por meio da disjunção entre a voz e a visualidade. Ou seja, o espectador somente tem acesso ao mundo por meio das representações dele filmadas pela perspectiva e olhar de um outro. No entanto, reconhecer que olhar também é uma ação significa dar valor ao gesto intrínseco ao poder de ver (Rancière, 2012). O filme-ensaio convoca ao espectador que perceba as imagens que seu olhar alcança relacionando-as a uma série de outras imagens visuais e mentais, de agora e de outros tempos. Por essa perspectiva, é possível que o espectador de uma posição distante assuma o papel de intérprete ativo, uma posição ativa em um mundo comum e, até mesmo, a função de cocriador da obra que experiencia.

Sendo assim, a fotografia atua em $A$ festa e os cães como o recurso de estilo que evidencia essa dupla mediação. Por um lado, as imagens utilizadas são registros pessoais e aparentemente descomprometidos do cotidiano do diretor. O ordenamento dessas fotografias por uma montagem predominantemente interna ao quadro operada por mãos que justapõem as fotos, com planos de longa duração, parece coincidir com a organização do pensamento do sujeito fragmentado que se reconhece em meio àquela profusão de imagens e vozes, frutos dos encontros experienciais a que se submeteu. $A$ festa e os cães medeia as experiências do cineasta com o mundo por intermédio das fotos, que são os registros visuais desses encontros.

Por outro lado, é por intermédio das fotos e do olhar de um outro que o espectador se encontra e repensa o seu lugar diante das questões universais que perfuram o filme. Parece-nos que a fixidez da imagem fotográfica é fator fundamental para que o espectador não apenas se torne pensativo, mas também crítico e emancipado. A festa e os cães medeia a experiência do espectador com as coisas do mundo por meio da fotografia ao convidá-lo a realizar o mesmo exercício: visitar as imagens de sua própria juventude atemporal e, junto a alguns amigos, refletir sobre os caminhos a serem tomados quando as despedidas são inevitáveis.

Em determinado momento do filme vemos uma fotografia em plano médio de uma jovem de cabelos curtos e camiseta vermelha, com óculos de armação grossa, olhando para baixo. Enquanto isso, ouvimos um diálogo entre a moça da imagem, Geane, e o sujeito que narra o filme: "Leo, porque 
você insiste tanto em tirar fotos minhas?" Ele responde: "Vai ver eu gosto de te ver envelhecer". Ocorre um corte seco para a mesma fotografia em um plano próximo, que nos aproxima do rosto de Geane e de sua testa franzida. Logo em seguida a ouvimos dizer, em tom melancólico: "Antes eu achava que eu seria a primeira a ir embora. Agora você que está indo e eu ainda continuo aqui". Uma fotografia entra em quadro da esquerda para a direita, em contra-plongée vemos um prédio em construção. O amigo a consola:"Mas a cidade muda Geane, quando eu voltar ela não vai nem estar mais no mesmo lugar".

É provável que a foto de Geane, feita por Leonardo, não tenha sido realizada com a intenção de ser utilizada em um filme. Parece mais resultado de um encontro qualquer entre os dois amigos. $\mathrm{O}$ interesse revelado por ele no envelhecimento da amiga, a partir do movimento de "voltar a ver" (Weinrichter, 2007) a fotografia, evidencia o ordenamento do pensamento impulsionado pelo manejo das fotos: é o filme mediando a experiência do cineasta com o mundo. Do mesmo modo, o espectador olha para a foto de Geane reconfigurando seus traços de "rostidade" e relacionando-a a alguma amizade, do passado ou do presente, que também foi impactada pela distância geográfica: é o filme mediando a experiência do espectador com o mundo.

Por esse motivo é importante que as imagens durem: para que o pensamento ganhe forma e uma relação profícua entre sujeito enunciador e sujeito espectador se estabeleça, uma relação efetivamente dialógica. 0 enunciador do filme-ensaio age em relação ao espectador de maneira a singularizá-lo dentro da multidão, "em vez de guiá-lo por meio de respostas emocionais e intelectuais, o ensaio pede a ele para se envolver individualmente com o filme, e refletir sobre o mesmo assunto que o autor está meditando" (Rascaroli, 2009, p. 34, tradução nossa). Em A festa e os cães, portanto, o encontro entre o slide-motion filme o filme-ensaio conflui simultaneamente para que o espectador seja pensativo e ambos os sujeitos se encontrem e se comuniquem a partir da experiência compartilhada por meio da obra.

\section{Das relações entre palavra e imagem}

As relações entre a palavra e a imagem, o dito e o visto, são primordiais para instaurar essa relação dialógica entre sujeito que enuncia e espectador. As constantes colisões entre a banda sonora e a imagética nos filmes-ensaio, que impedem uma ligação inconsciente entre imagem e som, servem como meio para a instalação da dúvida, para a criação de interstícios a serem preenchidos por aqueles que os veem (Blümlinger, 2007). Dessa forma, mais que manter uma relação hierárquica, imagem e som seguem de forma autônoma, nutrindo uma 
criativa interdependência. Cabe, portanto, ao espectador o exercício racional de realizar as ligações necessárias entre as imagens e sons presentes no filme, conectando fragmentos, ocupando intervalos, preenchendo com respostas os poros abertos das perguntas deixadas pela narrativa.

Nesse contexto dialógico é natural que a presença da voz do próprio cineasta tenha se tornado um dos traços estilísticos mais marcantes do filmeensaio. "Se alcança assim a condição necessária para que o cinema se produza como ensaio: voltar a ver a imagem, desnaturalizar sua função original [...] e vêla como representação, não ler somente o que representa" (Weinrichter, 2007, p. 28 , tradução nossa). A partir da voz do narrador temos acesso ao movimento de voltar a ver empreendido pelo realizador e, ao mesmo tempo, a possibilidade de acompanhar de perto o processo reflexivo enquanto ele toma forma, com suas incertezas e dúvidas.

Em A festa e os cães, a palavra - acessada pelas vozes do diretor e de seus amigos - parece simultaneamente buscar o resgate do instantâneo pelo contato com as fotografias, já percebidas como arquivos domésticos, e embalsamar o tempo cotidiano com os olhos voltados para o futuro: “...e na extensão do rolo de 36 poses, registrava isso que são meus últimos meses vivendo na cidade onde vivo", nos diz Mouramateus, enquanto vemos fotos de festas e da vida noturna em Fortaleza. "Habitualmente o resultado daquilo que eu encontrava após a revelação era também uma surpresa para mim. Num negativo de 36 poses, somente alguns milímetros unia lado a lado quilômetros de distância", finaliza. A voz parece, à primeira vista, trazer alguma instantaneidade às imagens fixas, como se auxiliasse o espectador a visualizar o movimento presente entre as imagens. Mas ao mesmo tempo o seu tom melancólico parece despedir-se das fotografias, e de todo o universo em que elas estão inseridas, como se o sujeito enunciador as olhasse com a intenção de guardá-las em um relicário de memórias.

Ou seja, as imagens são manipuladas pela mediação da voz do narrador que cria esse espaço reflexivo entre o realizador e o sujeito enunciador. No plano das estruturas de retórica, o ensaísta cinematográfico, portanto, é um autor extratextual que cria um sujeito enunciador, cujo papel é representar a visão do diretor para o filme. O enunciador, por sua vez, se valerá de um ou mais narradores para dar voz ao realizador (Rascaroli, 2009). Nesse sentido, o narrador do filmeensaio dá voz a opiniões pessoais que podem estar diretamente relacionadas ao autor extratextual e sua vida cotidiana, mas não necessariamente são compromissadas com a verdade exata dos fatos. A nível do compromisso textual, o comprometimento primordial do filme-ensaio está relacionado à expressão 
da reflexão pessoal do autor extratextual, compartilhada por intermédio do filme, por meio do sujeito enunciador e do(s) sujeito(s) narrador(es). Rascaroli sugere, portanto, que pensemos no filme-ensaio como um domínio, "como um modo, que é definido pelos compromissos textuais e estratégias retóricas acima discutidos; e explora as maneiras em que este modo é apropriado, manipulado, interpretado, modificado e reinventado por cineastas e videomakers" (Rascaroli, 2009, p. 39, tradução nossa).

São múltiplas as vozes que habitam $A$ festa e os cães, além da de Leonardo Mouramateus, para dar forma à reflexão proposta pelo filme. Vários amigos do diretor atuam como intercessores e narradores, emprestando suas vozes para o discurso arquitetado pelo sujeito enunciador: Geane, Clara, Kevin e Júnior.

Geane diz em determinado momento: "E depois das 4 da manhã, quando as portas da boate fecharem, a gente vai andar junto à beira-mar. Você não vai entrar no mar dessa vez, não vai me assustar. Vai ficar do meu lado, segurando minha mão. E você vai ver meu espetáculo. E quando eu pisar no palco, vou procurar teus olhos no meio do público. Vou falar as palavras do meu personagem, diretamente para você! E não pra qualquer uma daquelas 80 pessoas estranhas na plateia. Todas essas pessoas que não me conhecem, mas que me veem durante uma apresentação, e que veem uma parte de mim que eu não queria mostrar por ingresso, que eu não queria entregar de bandeja". Clara, em sua primeira fala, a interroga: "Você está bêbada?"

"Mas hoje, agora distante, eu sinto que se eu tivesse continuado ali, naquela cidade, talvez eu estivesse provando agora mesmo meu vestido de noiva e estivesse procurando por uma casa próxima à casa dos meus pais, para que vivêssemos eu e meu namorado roqueiro. Talvez estivesse dando um beijo no fim da cerimônia de casamento, para uma plateia composta pelo mesmo público que presenciou meu primeiro beijo. Minha mãe diz que o maior erro da vida dela foi ter me posto no balé", nos confessa Clara. No mesmo instante, Kevin a interrompe: "Quando eu te vejo numa foto dessa, a última coisa que eu penso é em uma bailarina. Você dança de olhos quase fechados".

Kevin reflete sobre as festas com seus amigos, enquanto ainda vivia em Rio Claro, no interior de São Paulo:"É como numa dessas músicas pop que falam sobre beber, cheirar, dar a louca, dançar com os amigos, beber mais um pouco, beber mais, não lembrar o nome da pessoa por quem você se apaixonou agora há pouco e depois beber mais um pouco. É como numa dessas músicas pop que diz que a gente nunca se entedia porque a gente tem muito tempo pra se encontrar. Agora pega qualquer uma dessas músicas e multiplica por 15. Eu podia contar sobre cada um dos fins de semana desses três anos, cada um dos 
rolês, antes de eu vir pra cá. Mas eu podia também contar sobre ter chegado aqui. Porque um dia todo mundo passou na faculdade. A Temps foi para Santos, a Tayci, pra São Paulo, o Rafa, pra Araras e eu vim pra cá. A Nayna e o Ozyo ainda estão lá. E uma vez a gente até voltou pra fazer uma festa, mas acho que a gente acabou enjoando. Na verdade eu nem sei se enjoo é a palavra certa".

Júnior, que parece ser um primo mais novo do diretor, o interpela: "Ninguém da família foi pra muito longe, só o tio Mauro, e agora tu". Calmamente, Mouramateus responde:"Eu já volto, Júnior". Cabe fazer a distinção de que a cena em que esse diálogo acontece é a única que rompe com o estatuto imagético que predomina em toda a obra, o qual temos nos dedicado a refletir. Nela, ao invés das fotos, acompanhamos diante da câmera o diálogo familiar em um quarto, com Júnior e Leonardo sentados de frente um para o outro. É como se o movimento, que durante todo o filme insistiu em habitar somente os intervalos entre as fotografias, irrompesse e invadisse a cena, garantindo a ela um outro tipo de temporalidade.

Apesar da multiplicidade de vozes há uma única visão sendo construída pelo sujeito enunciador por meios dos narradores: a do próprio diretor. Por mais que os textos utilizados pelas vozes pareçam revelar aspectos da vida de cada um dos personagens; a escolha, arranjo e escrita dessas palavras foram transpassadas pelo crivo e olhar criativo do autor extratextual, revelando menos deles mesmos do que das angústias do realizador. Assim, os demais narradores trazem sobretudo experiências relacionadas à partida de suas cidades de origem rumo a um novo lugar, Fortaleza; ou que giram em torno à partida do próprio diretor.

Reflexões que o enunciador convida aos demais narradores para que compartilhem com ele no sentido de prepará-lo para o mesmo exercício: partir de sua cidade natal em direção a um universo novo. Dessa forma, a palavra em A festa e os cães mais do que relacionar-se somente com as imagens que se dão a ver durante a projeção, parece revelar uma inversão da função da imagem. Não é apalavra que pensa a imagem, reduzindo sua potência de expressão. Mas a imagem que abandona seu usual caráter de suplemento, ao interromper e suspender a palavra, propondo-se a pensar.

\section{A propósito de uma imagem pensativa: fotografia e filme-ensaio}

A princípio, presume-se que uma imagem possa comportar-se apenas como objeto de pensamento. Não é pressuposto que ela seja capaz de pensar. No entanto, tendemos a crer que as fotografias de $A$ festa e os cães se proponham a tal. "Imagem pensativa, então, é uma imagem que encerra 
pensamento não pensado, pensamento não atribuível à intenção de quem a cria e que produz efeito sobre quem a vê sem que este a ligue a um objeto determinado" (Rancière, 2012, p. 103). Ou seja, no caso do filme-ensaio em questão, o sentido das fotografias, que compreendemos como "imagens pensativas" (Rancière, 2012) não pertence completamente ao realizador nem ao espectador. Complexificando a relação dialógica mantida entre ambos, a imagem pensativa interrompe a mera atividade de transmissão de informação, suspendendo qualquer tipo de caráter eminentemente conclusivo.

A pensatividade das imagens de $A$ festa e os cães é proveniente do produtivo encontro de dois regimes de expressão que dialogam intensamente, sem abrirem mão de sua autonomia e potência expressivas: a fotografia e o cinema. Como vimos anteriormente, o espectador é mantido em um contínuo estado de suspensão pela utilização das fotos como principal material de composição da narrativa cinematográfica. Isto é, a imobilidade da fotografia fixa é incorporada ao filme, sem que ele abra mão de sua principal característica expressiva: o movimento, que passa a ser conquistado pelos interstícios entre as imagens.

Dessa forma, percebemos tais intervalos como principal índice visual e fruto do entrecruzamento criativo desses diferentes regimes de expressão: fotografia e cinema. Pela intervenção deles, o espectador é convidado simultaneamente a tornar-se pensativo e participar de uma conversa com o ensaísta audiovisual, contribuindo para a criação de um significado textual eminentemente aberto e plural. Nos interstícios outras imagens são ativadas pelos que veem o filme, acionadas pelas vozes dos narradores: imagens de arquivo, guardadas na memória, e imagens do instantâneo, criadas pelo movimento imanente ao intervalo entre uma foto e outra.

“Então comecei a achar que aquelas fotos, essas fotos, tiradas por nós, falavam um pouco mais do que só sobre festas ou sobre cães", nos confessa Leonardo Mouramateus, em determinado momento do filme. Esse "um pouco mais" que inquieta o narrador nos parece ser aquilo que vai além do que o realizador pensa sobre a imagem, ou do que nós como espectadores somos capazes de compreender: trata-se daquilo que a imagem pensa. Sendo assim, os arranjos singulares entre esses regimes expressivos, promovem diálogos criativos, aproximações e afastamentos, que garantem às imagens de $A$ festa e os cães esse caráter de pensatividade. Pois a imagem não é pensativa por ser fotográfica ou cinematográfica, mas por atravessando-se sem se homogeneizar, designar "algo que resiste ao pensamento, ao pensamento daquele que a produziu e daquele que procura identificá-lo" (Rancière, 2012, p. 124). 


\section{Do espectador pensativo à imagem pensativa}

Segundo Bellour, a presença da foto na tela de cinema é capaz de interromper o fluxo narrativo, gerando um efeito de suspensão no ritmo do filme. "A foto me subtrai da ficção do cinema, apesar de participar dela, apesar de aumentá-la. Criando uma distância, um outro tempo, a foto me permite pensar no cinema" (Bellour, 1997, p. 86). Tendo esse plano de fundo em vista, partimos da seguinte problematização: quais os possíveis desdobramentos e/ou efeitos gerados pelo uso da fotografia fixa na construção de um filme-ensaio? Por meio de uma análise fílmica do curta-metragem $A$ festa e os cães, propusemonos a averiguar a hipótese de que o uso da imagem fixa no filme-ensaio, em particular, para além de reforçar a convocação de um "espectador pensativo" (Bellour, 1997), é capaz de gerar uma "imagem pensativa" (Rancière, 2012).

Compreendemos que o cinema pode, em alguma medida, se apropriar de todas as coisas que são postas diante da câmera. Ao construir determinada narrativa, o realizador medeia as relações que o espectador terá com as representações das coisas do mundo, sendo capaz de propor, inclusive, que enquanto espectadores pensemos sobre essas mediações - entre outras formas, a partir dessa distância e suspensão que a fotografia fixa gera na relação que temos com o filme. Dessa maneira, confirmamos que a fotografia poderia ser percebida como indício visual de um convite ao espectador para exercitar o pensamento e a reflexão dentro do cinema.

A fotografia, por essa perspectiva, ao ser incorporada de maneira predominante pela narrativa cinematográfica de $A$ festa e os cães, é utilizada como esse elemento estético, com uma força disruptiva intrínseca, que nos desloca de um lugar de espectatorialidade confortável, assinalando a dupla mediação à qual estamos submetidos. Ou seja, por um lado, a construção da narrativa medeia a experiência subjetiva do cineasta com o mundo, tendo a obra em si como a figuração desse processo; por outro, o filme-ensaio, enquanto obra, medeia a experiência dos espectadores com as coisas do mundo por meio da visualidade e da voz, da palavra e da imagem.

Ao lidar com as fotografias como se não fossem suas, o realizador produz a distância reflexiva necessária para modificar o valor privado e íntimo das mesmas. Valendo-se especialmente da relação entre texto e imagem, comentário verbal e fotografia, banda sonora e imagética - portanto, sobretudo, da montagem; A festa e os cães estabelece essa mediação que transfigura as fotos em elementos moldáveis, flexíveis, maleáveis. Pela forma em que esses materiais são ordenados, o realizador aos poucos dá forma ao seu pensamento. 
No entanto, essas fotografias, ao relacionarem-se não somente com as que a antecedem e sucedem, mas com todas as demais por relações de vizinhança, bem como com o texto verbal, revelam uma potência particular que parece escapar às intenções do cineasta. Logo, algo acontece para além das contínuas suspensões temporais, que convidam ao pensamento, a cada nova fotografia que se revela.

Por essa via, o espectador é chamado a engajar-se em uma relação dialógica e dinâmica com o texto e o sujeito que o enuncia, a completar as lacunas, a"tornar-se ativo, intelectualmente e emocionalmente, e interagir com o texto" (Rascaroli, 2009, p. 35). Interação essa que será responsável por construir o sentido do filme de forma compartilhada, já que o sujeito enunciador realiza uma reflexão declaradamente pessoal a partir do comentário verbal e das fotografias.

Por fim, o filme-ensaio não transmite ao espectador o saber ou experiência do realizador em sua completude, comportando-se como esse terceiro elemento, cujo sentido não está plenamente depositado nem na intenção do cineasta nem na leitura do espectador. São os sentidos das fotografias em si que, em certa medida, revelam-se em construção permanente: não estão mais ligados às intenções do ensaísta, tampouco às capacidades perceptivas do espectador somente; mas intrínsecos à própria obra, às próprias fotografias, às imagens em si: pensativas.

\section{Referências}

BELLOUR, Raymond. Entre-imagens: foto, cinema, vídeo. Campinas/SP: Papirus, 1997.

BLÜMLINGER, Christa. Leer entre las imágenes. In: WEINRICHTER, Antonio (org.). La forma que piensa: tentativas en torno al cine-ensayo. Pamplona: Gobierno de Navarra, 2007.

COMOLLI, Jean-Louis. Ver e poder: a inocência perdida - cinema, televisão, ficção, documentário. Belo Horizonte: UFMG, 2008.

CORRIGAN, Timothy. O filme-ensaio: desde Montaigne e depois de Marker. Campinas/ SP: Papirus, 2015.

HAUSKEN, Liv. The Temporalities of the Narrative Slide Motion Film. In: Eivind Røssaak (Org.). Between Stillness and Motion: Film, Photography, Algorithms. Amsterdam: Amsterdam University Press, 2011.

KONIGSBERG, Ira. Diccionario Técnico Akal de Cine. Madrid: Ediciones Akal, 2004. 
RANCIÈRE, Jacques. O espectador emancipado. São Paulo:WMF Martins Fontes, 2012.

RASCAROLI, Laura. The personal camera: subjective cinema and thees say film. New York: Wallflower Press, 2009.

WEINRICHTER, Antonio (org.). La forma que piensa: tentativas en torno al cine-ensayo. Pamplona: Gobierno de Navarra, 2007.

Recebido em: 25/8/2016

Aceito em: 22/9/2016

Endereço do autor:

Rafael de Almeida <rafaeldealmeidaborges@gmail.com>

Curso de Cinema e Audiovisual da Universidade Estadual de Goiás (UEG)

Avenida Prof. Alfredo de Castro, s/nº - Bairro Chácara do Governador

74855-130 - Goiânia (GO) - Brasil 